\title{
Reconstruction versus conservative treatment after rupture of the anterior cruciate ligament: cost effectiveness analysis
}

\author{
Mazda Farshad ${ }^{1 *}$, Christian Gerber ${ }^{1}$, Dominik C Meyer ${ }^{1}$, Alexander Schwab², Patricia R Blank ${ }^{3}$ and Thomas Szucs ${ }^{3}$
}

\begin{abstract}
Background: The decision whether to treat conservatively or reconstruct surgically a torn anterior cruciate ligament $(\mathrm{ACL})$ is an ongoing subject of debate. The high prevalence and associated public health burden of torn $A C L$ has led to continuous efforts to determine the best therapeutic approach. A critical evaluation of benefits and expenditures of both treatment options as in a cost effectiveness analysis seems well-suited to provide valuable information for treating physicians and healthcare policymakers.

Methods: A literature review identified four of 7410 searched articles providing sufficient outcome probabilities for the two treatment options for modeling. A transformation key based on the expert opinions of 25 orthopedic surgeons was used to derive utilities from available evidence. The cost data for both treatment strategies were based on average figures compiled by Orthopaedic University Hospital Balgrist and reinforced by Swiss national statistics. A decision tree was constructed to derive the cost-effectiveness of each strategy, which was then tested for robustness using Monte Carlo simulation.
\end{abstract}

Results: Decision tree analysis revealed a cost effectiveness of 16,038 USD/0.78 QALY for ACL reconstruction and 15,466 USD/0.66 QALY for conservative treatment, implying an incremental cost effectiveness of 4,890 USD/QALY for ACL reconstruction. Sensitivity analysis of utilities did not change the trend.

Conclusion: $\mathrm{ACL}$ reconstruction for reestablishment of knee stability seems cost effective in the Swiss setting based on currently available evidence. This, however, should be reinforced with randomized controlled trials comparing the two treatment strategies.

\section{Background}

Rupture of the anterior cruciate ligament (ACL) changes the kinematics of the knee [1] and often results in instability with accompanying functional disability and pain [2-22]. Although there are more than 2000 scientific articles in the literature [23] illuminating several aspects of ACL rupture, there is no consensus on the optimal treatment. Whereas some authors reported adequate outcomes after operative treatment using various techniques [8,13,24-44], others documented sufficient clinical results after conservative treatment with various protocols of immobilization and physiotherapy [4,45-64]. Although several instruments and scoring systems [65-69] have

\footnotetext{
* Correspondence: mazda.farshad@balgrist.ch

'Department of Orthopedic Surgery, University of Zürich, Balgrist University Hospital, Zürich, Switzerland

Full list of author information is available at the end of the article
}

been developed to facilitate standardized reporting and comparison of differently treated patients, decision towards one or the other, namely, conservative or surgical treatment seems currently challenging [14] due to lack of randomized controlled trials with information on long-term results [70].

Most surgeons advocate ACL reconstruction for patients with ACL rupture associated with subjective instability whereas some orthopedic surgeons routinely favor conservative treatment of ACL ruptures. Thus there is still controversy on this common injury with an estimated incidence of approximately 1500/100,000 person-years in Switzerland, 1200/100,000 person-years in New Zealand [71], and 3000/100,000 person-years in the United States [23]. The occurrence of ACL ruptures depends on sex, age, and sports activities of those affected [72]. The Swiss National Insurance System for Injuries (UVG), which 
covers half the Swiss population, provides around 200-250 million US dollars equivalent yearly for patients with ACL injuries, including $40 \%$ of direct treatment costs.

A critical evaluation of benefits and expenditures of the two treatment options so as to provide valuable information for treating physicians and healthcare policymakers is in progress. Technical arguments appear unable to determine superiority of one or the other strategy and complementary research using economic and public health approaches including assessment of quality of life, direct cost, and cost effectiveness is necessary. Although cost effectiveness would significantly affect the decision toward one or other strategy, such studies for this common injury are rare [73,74]. A cost effectiveness analysis would allow rational allocation of limited resources and resolve an uncertainty that might potentially have been created by setting the focus on purely medical factors rather than economics aspects.

Gottlob et al [75] reported that in young adults in the United States, surgical treatment of ACL ruptures was more cost-effective than conservative treatment. However, due to lack of studies comparing the two treatment options in the same study groups at that time (1999) as well as more recent advances particularly in the surgical treatment of ACL ruptures, the results must be interpreted with caution and might not represent the current status. Although several authors aimed to compare surgical with conservative treatment [2-22], these reports are difficult to use for cost effectiveness analysis due to lack of necessary information and use of outdated surgical techniques. The purpose of the present cost-utility analysis was to identify the more cost effective treatment option for ACL ruptures in patients at an average age 3035 years from the viewpoint of third party payers in the Swiss setting by the use of evidence created by studies comparing directly both treatment options in the same study population.

\section{Methods}

\section{Literature review and extraction of effectiveness data}

We retrieved 7076 articles in Medline by searching with the keywords "anterior cruciate ligament" and "knee" screening in "any field" and/or "long term" in "any field" without limitation of the study type. From those articles further search by the keywords "conservative" or "non operative" and "surgical" or "operative" identified 128 articles. Each article was screened and excluded if conservative treatment and ACL reconstruction were not directly compared, no data could be abstracted for conversion of reported outcomes to the activity score, the population of investigation comprised children or adolescents, and if the technique for surgical repair was neither semitendinous tendon grafting nor bone patellar tendon bone autograft. Additionally, reviews $[10,14,50,74]$ were screened; four additional articles $[4,11,17,21]$ were identified as articles comparing conservative versus operative treatment. After application of the exclusion criteria, four articles $[5,7,13,19]$ were used for further analysis (Figure 1 ).

\section{Compilation of available evidence and transformation to utility}

To assess the utilities based on activity levels as suggested and validated by Gottlob et al clinical vignettes have been designed to match Gottlob's levels of activity as I-IV, where I is a patient with symptomatic activities of daily living (ADL), II someone who can perform ADLs without symptoms but no sports, III a patient with knee symptoms when performing mildly stressful sports such as jogging, swimming, and cycling, and IV someone with knee symptoms when doing moderately stressful sports activities such as baseball, alpine skiing, and dance. Activity levels 0 and $\mathrm{V}$ were assumed to score lowest and highest, respectively, on all scores. Four hypothetical patients were constructed based on different levels of activities after rupture of the ACL to simulate typical situations seen in daily practice. A questionnaire including the Health Utility Index (HUI)-III for utility values, IKDC subjective score, and Lysholm and Tegner score was created and 25 orthopedic surgeons were asked to fill the questionnaire for each hypothetical patient as proxies for all patients they had treated and who would fit in that hypothetical scenario. The opinions of the surgeons were weighted on their experience with ACL patients for analysis. A transformation key was developed to transform the reported outcomes from the available studies to utility values and utility values were assigned for corresponding activity levels 0 to $\mathrm{V}$ as described in detail elsewhere [76]. The mean age and follow-up length of the abstracted confined population of the four retracted articles were calculated weighted according to the sample size (Table 1).

\section{Cost data}

Cost data were based on average cost of treating patients with ACL ruptures at the Department of Orthopedic Surgery, Orthopaedic University Hospital Balgrist (University of Zürich, Switzerland). Hospitalization data were analyzed for 254 consecutive patients who underwent ACL reconstruction between 2005 and 2009. From those, the last 31 consecutive cases representing the cohort of 2009 were analyzed in detail. The data of the remaining 223 patients (2005-08) were used to assure that the cohort of 2009 was representative. For the outpatient portion of the treatment before and after ACL reconstruction and for conservative treatment the experts were asked to assess what kind of resources the average patient with torn ACL experiencing joint instability would use in what frequency. Both used resources and prices per unit of each resource were extracted from detailed cost statistics 


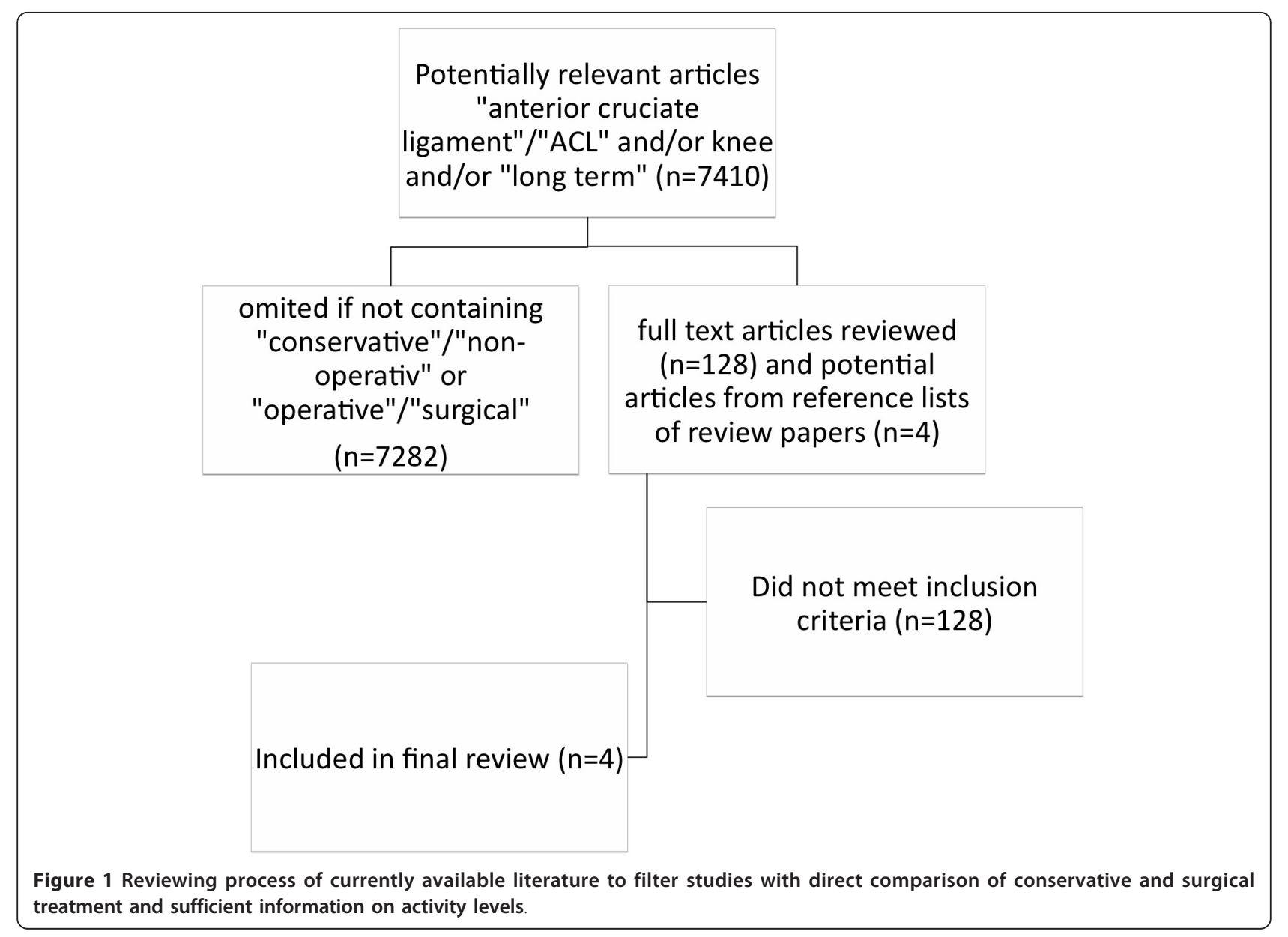

Table 1 Distribution of level of activities of a constructed population based on available studies after either operative or conservative treatment of torn ACL

\begin{tabular}{|c|c|c|c|c|c|c|c|c|}
\hline & \multirow[b]{2}{*}{ Patients with activity data (n) } & \multirow[b]{2}{*}{ Age (years) } & \multirow[b]{2}{*}{ Follow Up (months) } & \multicolumn{5}{|c|}{ Activity level (Gottlob et al) } \\
\hline & & & & $\begin{array}{c}\text { Class I } \\
(\%)\end{array}$ & $\begin{array}{c}\text { Class II } \\
(\%)\end{array}$ & $\begin{array}{c}\text { Class III } \\
(\%)\end{array}$ & $\begin{array}{c}\text { Class IV } \\
(\%)\end{array}$ & $\begin{array}{c}\text { Class V } \\
(\%)\end{array}$ \\
\hline \multicolumn{9}{|l|}{ operative } \\
\hline Finke et al (2001) & 46 & 34 & 132 & 2 & 12 & 12 & 20 & 0 \\
\hline Diekstall et al (1999) & 60 & 27.9 & 51 & 5 & 6 & 6 & 11 & 32 \\
\hline Kessler et al (2008) & 60 & 30.7 & 140 & 5 & 6 & 6 & 11 & 32 \\
\hline Seitz et al (1994) & 63 & 25 & 102 & 0 & 0 & 7 & 56 & 0 \\
\hline mean/Sum & 229 & 28 & 89 & 12 & 24 & 31 & 98 & 64 \\
\hline$\%$ & & & & 5.2 & 10.5 & 13.5 & 42.8 & 27.9 \\
\hline \multicolumn{9}{|l|}{ conservative } \\
\hline Finke et al (2001) & 25 & 32 & 140 & 11 & 6.5 & 6.5 & 1 & 0 \\
\hline Diekstall et al (1999) & 49 & 23.8 & 53 & 7 & 7.5 & 7.5 & 20 & 7 \\
\hline Kessler et al (2008) & 60 & 30.7 & 140 & 5 & 6 & 6 & 11 & 32 \\
\hline Seitz et al (1994) & 21 & 28 & 102 & 0 & 3 & 12 & 6 & 0 \\
\hline mean/Sum & 155 & 27 & 90 & 23 & 23 & 32 & 38 & 39 \\
\hline$\%$ & & & & 14.8 & 14.8 & 20.6 & 24.5 & 25.2 \\
\hline
\end{tabular}


provided by Orthopaedic University Hospital Balgrist. Furthermore, experts were asked to provide names of typical patients for each of the surgical and conservative arm to validate the calculations that were derived from statistical analysis. In addition, cost data by the Swiss National Insurance for Accidents (UVG) were used to confirm the ability of our cost data to represent the average Swiss patient undergoing either surgical or conservative treatment for ACL rupture.

Direct costs of potential long-term complications after ACL rupture, namely, meniscal lesions and osteoarthritis were calculated based on the analysis of 73 and 406 consecutive patients who underwent treatment for meniscus lesions (3847 USD) or osteoarthritis (total knee prosthesis, 14,826 USD) during 2006-09, which were however not necessarily identified as direct complications of ACL rupture and inpatient costs only. The perioperative costs were assumed in the same range as for ACL surgery (2535 USD) (Table 2) and were added to the in-hospital costs for each complication.

Prices per unit are documented in USD calculated by conversion of Swiss Francs (CHF) by a factor of 1.15 based on the exchange rate as of May 3, 2010.

\section{Modeling}

A decision tree was constructed using the software Treeage Pro 2009 over a time horizon of 90 months based on the constructed study population (Table 1). In the surgical arm, patients undergoing ACL reconstruction without complications (osteoarthritis or meniscal lesions) were distributed to activity levels $0-\mathrm{V}$ on the basis of currently available evidence (Table 1). The corresponding utility values[76] were used for each class of activity. In $3.5 \%$ of patients, ACL-reconstruction failed and re-reconstruction was needed. For those patients the activity level was assumed one class lower than before failure, except patients in class 1 remained in the same class. The same approach was used for construction of the conservative arm with the according probabilities and utility value for each activity class. In the model $16 \%$ of conservatively treated patients required surgical ACL reconstruction. Other studies have shown even higher (up to 39\%) need for ACL reconstruction in conservatively treated patients [70]. The average costs of the surgical arm without complication were used for patients added to the costs of initial conservative therapy.

The probability of sequelae associated with ACL rupture for patients after ACL reconstruction was set at $34 \%$ on the basis of the retracted articles that could provide sufficient long-term information $[8,19]$. From those $34 \%$, the major fraction was osteoarthritis (86\%) followed by meniscal lesions (14\%). For patients who decided to undergo conservative treatment, the probability of developing complications was higher (77\%). Their ratio of osteoarthritis to meniscal lesions, however, was not the same (74\% and $26 \%$ ). It was assumed that all complications needed to undergo surgical therapy and the costs of surgical therapy for meniscal lesions and osteoarthritis were added to those of ACL repair or conservative treatment in such cases. Patients with sequelae of each treatment method were assumed in activity class II.

Table 2 Total direct costs of operative and conservative treatment of a torn ACL

\begin{tabular}{|c|c|c|c|c|}
\hline & Resource & amount & costs (USD) & costs per unit (USD) \\
\hline \multirow[t]{10}{*}{ Surgical treatment } & Outpatient visit (15 min) & $5(2-6)$ & 718 & 144 \\
\hline & Xray (Knee, 3 views) & $1(2-3)$ & 128 & 128 \\
\hline & MRI & 1 & 419 & 419 \\
\hline & In-hospital stay and OR & 4.8 days & 7391 & 7391 \\
\hline & Medication ambulant & & & \\
\hline & low molecular heparin & 16 days $1 /$ day & 150 & 9 \\
\hline & analgesic agents & 16 days, 3/day & 157 & 3 \\
\hline & Physiotherapy units & $14(9-27)$ & 672 & 42 \\
\hline & Orthesis & 1 & 291 & 291 \\
\hline & Total & & 9926 & \\
\hline \multirow[t]{9}{*}{ Conservative treatment } & Outpatient visit (15 min) & $3(2-10)$ & 431 & 144 \\
\hline & X-ray (Knee, 3 views) & $1(1-2)$ & 128 & 128 \\
\hline & MRI & 1 & 419 & 419 \\
\hline & Medication & & & \\
\hline & low molecular heparin & 21 days, 1/day & 197 & 9 \\
\hline & analgesic agents & 21 days, 3/day & 205 & 3 \\
\hline & Physiotherapy units & $18(9-27)$ & 864 & 42 \\
\hline & Orthesis & 1 & 291 & 291 \\
\hline & total & & 2535 & \\
\hline
\end{tabular}


Sensitivity analysis was performed to test the robustness of the model. The uncertainty for the assigned utility values to the activity classes was tested for robustness by Monte Carlo probabilistic sensitivity analysis by using 10,000 sets of parameter values randomly sampled from a normal distribution (normal distribution and standard deviations (SD) as gained from the literature[76]). Parameters covered included all utility values. Furthermore, the incremental cost effectiveness was calculated for the worst-case assumption where no attention would be given to complications such as meniscal lesions and osteoarthritis.

\section{Results}

Extraction of effectiveness data and compilation to utility The available literature was sufficient to allow construction of a population of 384 patients (229 treated surgically and 155 conservatively) with a mean follow-up after surgical and conservative treatment of 89 months and 90 months, respectively. Using the transformation key based on the experts survey[76], level of activities could be assigned to patient groups of extracted articles (Table 1). The proportion of patients with high levels of activity (IV and V) was higher after surgical (70.7\%) than conservative treatment (49.7\%) (Table 1).

\section{Costs}

Direct costs were higher in surgically (9926 USD) than in conservatively treated patients (2535 USD). The main contributor to the cost of ACL reconstruction was in-hospital stay with a mean of 4.8 days (7391 USD) (Table 2). The costs of ACL reconstruction extracted and analyzed on the basis of data compiled by Orthopaedic University Hospital Balgrist overestimated as expected the values provided by the Swiss UVG, with 8673 CHF (7536 USD) for both surgically and conservatively-treated patients.

\section{Cost effectiveness}

Decision tree analysis revealed a rate of 16,038 USD/0.78 QALY for ACL reconstruction and 15,466 USD/0.66 QALY for conservative treatment, implying a cost effectiveness for the two treatments of 20,612 USD/QALY (SD: 1941 USD/QALY) and 23,391 USD/QALY (SD: 5603 USD/QALY), respectively, and an incremental cost effectiveness (the incremental cost divided by the incremental effectiveness, not the difference of cost effectiveness of one minus the other strategy) of 4890 USD/QALY for ACL reconstruction (Table 3).
Sensitivity analysis by Monte Carlo probabilistic simulation for simultaneously varying utility values documented 16,038 USD with a utility value of $0.78 \pm 0.07$ for surgical therapy and 15,466 USD with $0.66 \pm 0.13$ for conservative therapy according to a cost effectiveness of $20,687 \pm 1959$ USD/QALY and 24,467 \pm 5656 USD/ QALY, respectively. At a willingness to pay/QALY of 10000 USD the reconstruction became the preferred strategy (Figure 2). Additional probabilistic sensitivity analyses are shown in Figure 3.

In the worst-case scenario, not accounting for sequelae such as late meniscal lesions or development of osteoarthritis, the incremental cost effectiveness would be 68,715 USD/QALY for surgical treatment.

\section{Discussion}

The decision whether to treat conservatively or reconstruct surgically a torn ACL has been debated throughout the history of knee surgery. The high prevalence and associated public health burden of torn ACL has led to continuous arguments in favor of one or the other strategy, which produced, however, no clear solution. Although thousands of studies have been published in regard to ACL [23], a critical evaluation of benefits and expenditures of both treatment options to provide valuable information for treating physicians and healthcare policymakers has not been performed [74]. Here, we analyzed the cost effectiveness of the two procedures in the Swiss setting and found surgical reconstruction to be cost effective assuming the patient has from symptoms such as the knee giving way, pain, or instability.

The results of our analysis must, however, be interpreted with caution. First, the information of clinical outcome or effectiveness for each treatment approach was based on compiled data from reported studies. Efforts were made to review systematically the currently available literature (Figure 1) so as to find the most suitable sources of information. Although the retracted studies $[5,7,13,19]$ were potentially heterogeneous and were not randomized controlled trials, they did compare the two treatment strategies in the same experimental setting and provide sufficient outcome data for abstraction to utility values.

Second, the decision tree is a model only. On the other hand, sensitivity analysis showed a very robust model. The most sensitive determinant changing the incremental cost effectiveness for surgical therapy $>10$ fold to 68,715 USD/QALY was removal of sequelae of

Table 3 Incremental cost effectiveness analysis for reconstructive therapy of torn ACL

\begin{tabular}{ccccccc}
\hline Strategy & Cost & Incremental Cost & Effect & Incremental Effect & Cost Effectiveness & Incremental Cost Effectiveness \\
\hline Conservative & USD 15466 & & QALY 0,66 & & USD/QALY 23391 & \\
Reconstruction & USD 16038 & USD 572 & QALY 0,78 & QALY 0,12 & USD/QALY 20612 & USD/QALY 4890 \\
\hline
\end{tabular}




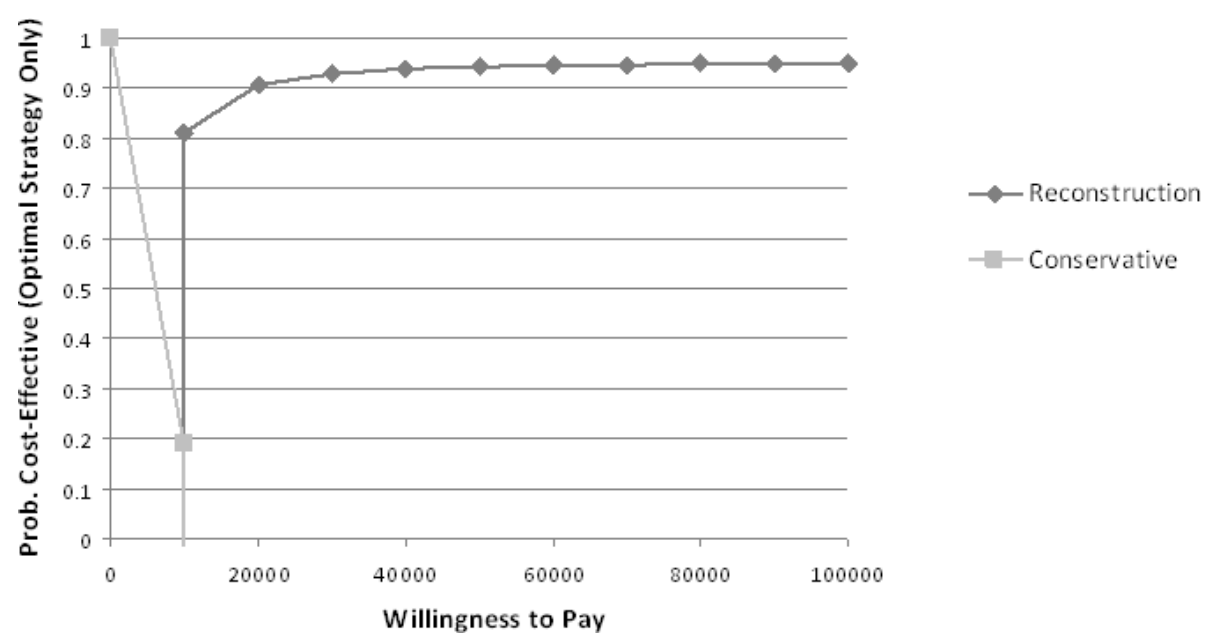

Figures 2 The cost-effectiveness acceptability frontier shows the probabilistic sensitivity analysis-based on the probability of surgically and conservatively treated ACL patients of being cost-effective. For different willingness to pay thresholds, a different strategy is preferred. For each threshold, only the probability for the optimal strategy is shown.

torn ACL. This however is an unrealistic scenario [7,19]. Changes in the kinematics of gait produced by a deficient ACL have been described to result in subsequent osteoarthritis relatively unrelated to whether a reconstruction has been performed [77,78]. Meniscal lesions are commonly concomitant to ACL ruptures and also play a contributive role in development of osteoarthritis $[79,80]$. ACL-deficient, conservatively treated patients do need more often surgical treatment for meniscal lesions $[5,7,13,19]$. The results of studies that might describe no difference in sequelae for either treatment strategy should be interpreted with caution to a common limitation being a selection bias of patients with less severe injuries to the conservative arm of the study. Further, the severity of osteoarthritis should be considered in studying long-term results of both treatment options; while the overall rate of osteoarthritis might not significantly be related to the treatment procedure, more severe degeneration has been reported in patients undergoing conservative treatment [81]. It is however unquestionable that some patients will benefit more from ACL reconstruction than others. How and when to select patients for surgery remain strongly disputed issues. Stratification regarding the need for surgery has not been possible in the current analysis because there are no uniform guidelines or consensus.

Third, the cost of the conservative arm seems underestimated. Although hospital infrastructure, administration, and organization costs were mainly covered by surgically treated patients with in-hospital stays, these are also significantly used by ambulatory patients such as those whose ACL is conservatively treated.

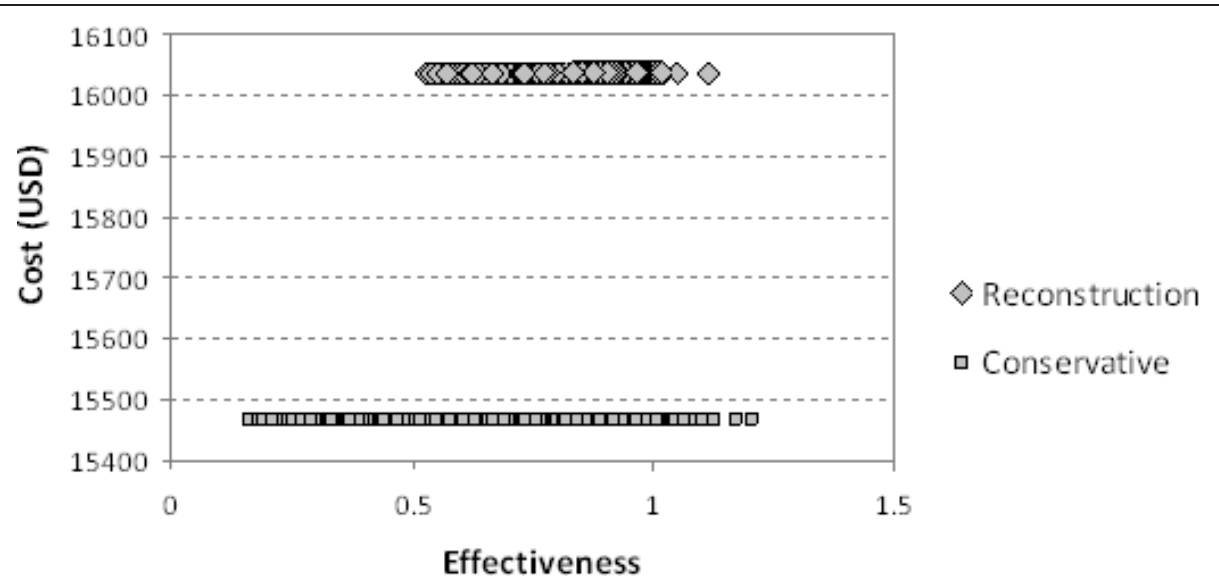

Figure 3 The cost-effectiveness scatter plot uses the cost-effectiveness plane to plot the cost and effectiveness pair for each recalculation of the model with 10,000 runs for each strategy. 


\section{Conclusion}

ACL reconstruction is cost effective. Our calculated incremental cost effectiveness of 4890 USD/QALY is in good agreement with the hitherto only available analysis performed by Gottlob et al (5857 USD/QALY) [74]. However, although the results of this study might contribute to informed decision making for health policymakers, the individual situation of the patient must be respected when suggesting one or the other strategy.

\section{Acknowledgements}

The authors want to thank the orthopedic surgeons of Balgrist University Hospital for their contribution in regard to development of the transformation key.

\section{Author details}

'Department of Orthopedic Surgery, University of Zürich, Balgrist University Hospital, Zürich, Switzerland. ${ }^{2}$ Balgrist University Hospital, Financial Management and Controlling, University of Zürich, Balgrist University Hospital, Zürich, Switzerland. ${ }^{3}$ Institute of Pharmaceutical Medicine, University of Basel, Basel, Switzerland.

\section{Authors' contributions}

All authors have made substantial contributions to this study; MF was involved in conception and design and the acquisition of data, analysis and interpretation of data and in drafting the manuscript. GC was involved in conception and design and the interpretation of data, revising the manuscript critically for important intellectual content and supervision. DCM was involved in conception and design and the acquisition of data, analysis and interpretation of data and in drafting the manuscript. AS was involved in the acquisition of data, interpretation of data and revising the manuscript critically for important intellectual content. PB was involved in analysis and interpretation of data and revising the manuscript critically for important intellectual content. TS was involved in conception and design and interpretation of data and revising the manuscript critically for important intellectual content and supervision. All authors read and approved the final manuscript.

\section{Competing interests}

The authors declare that they have no competing interests.

Received: 16 November 2010 Accepted: 19 November 2011

Published: 19 November 2011

\section{References}

1. Van de Velde SK, Gill TJ, Li G: Evaluation of kinematics of anterior cruciate ligament-deficient knees with use of advanced imaging techniques, three-dimensional modeling techniques, and robotics. J Bone Joint Surg Am 2009, 91(Suppl 1):108-114.

2. Andersson C, Odensten M, Gillquist J: Knee function after surgical or nonsurgical treatment of acute rupture of the anterior cruciate ligament: a randomized study with a long-term follow-up period. Clin Orthop Relat Res 1991, 264: 255-263

3. Clancy WG Jr, Ray JM, Zoltan DJ: Acute tears of the anterior cruciate ligament. Surgical versus conservative treatment. J Bone Joint Surg Am 1988, 70(10):1483-1488.

4. Daniel DM, Stone ML, Dobson BE, Fithian DC, Rossman DJ, Kaufman KR: Fate of the ACL-injured patient. A prospective outcome study. Am J Sports Med 1994, 22(5):632-644.

5. Diekstall $P$, Rauhut F: [Considerations for the indications for anterior cruciate ligament reconstruction. Results of conservative versus operative treatment]. Unfallchirurg 1999, 102(3):173-181.

6. Fink $C$, Hoser $C$, Benedetto KP: [Sports capacity after rupture of the anterior cruciate ligament-surgical versus non-surgical therapy]. Aktuelle Traumatol 1993, 23(8):371-375.
7. Fink C, Hoser C, Benedetto KP: [Development of arthrosis after rupture of the anterior cruciate ligament. A comparison of surgical and conservative therapy]. Unfallchirurg 1994, 97(7):357-361.

8. Fink C, Hoser C, Hackl W, Navarro RA, Benedetto KP: Long-term outcome of operative or nonoperative treatment of anterior cruciate ligament rupture-is sports activity a determining variable? Int J Sports Med 2001, 22(4):304-309.

9. Frobell RB, Lohmander LS, Roos EM: The challenge of recruiting patients with anterior cruciate ligament injury of the knee into a randomized clinical trial comparing surgical and non-surgical treatment. Contemp Clin Trials 2007, 28(3):295-302.

10. Hinterwimmer S, Engelschalk M, Sauerland S, Eitel F, Mutschler W: [Operative or conservative treatment of anterior cruciate ligament rupture: a systematic review of the literature]. Unfallchirurg 2003, 106(5):374-379.

11. Jerosch J, Schaffer C, Prymka M: [Proprioceptive abilities of surgically and conservatively treated knee joints with injuries of the cruciate ligament]. Unfallchirurg 1998, 101(1):26-31.

12. Karanikas K, Arampatzis A, Bruggeman GP: [Conservative versus operative treatment after ACL-rupture: influence on the muscle strength capability of the lower extremity]. Sportverletz Sportschaden 2005, 19(1):15-21.

13. Kessler MA, Behrend H, Henz S, Stutz G, Rukavina A, Kuster MS: Function, osteoarthritis and activity after ACL-rupture: 11 years follow-up results of conservative versus reconstructive treatment. Knee Surg Sports Traumatol Arthrosc 2008, 16(5):442-448.

14. Linko E, Harilainen A, Malmivaara A, Seitsalo S: Surgical versus conservative interventions for anterior cruciate ligament ruptures in adults. Cochrane Database Syst Rev 2005, , 2: CD001356.

15. Meuffels DE, Favejee MM, Vissers MM, Heijboer MP, Reijman M, Verhaar JA: Ten year follow-up study comparing conservative versus operative treatment of anterior cruciate ligament ruptures. A matched-pair analysis of high level athletes. Br J Sports Med 2009, 43(5):347-351.

16. Meunier A, Odensten M, Good L: Long-term results after primary repair or non-surgical treatment of anterior cruciate ligament rupture: a randomized study with a 15-year follow-up. Scand J Med Sci Sports 2007 17(3):230-237.

17. Odensten M, Hamberg P, Nordin M, Lysholm J, Gillquist J: Surgical or conservative treatment of the acutely torn anterior cruciate ligament. A randomized study with short-term follow-up observations. Clin Orthop Relat Res 1985, 198: 87-93.

18. Scavenius M, Bak K, Hansen S, Norring K, Jensen KH, Jorgensen U: Isolated total ruptures of the anterior cruciate ligament-a clinical study with long-term follow-up of 7 years. Scand J Med Sci Sports 1999, 9(2):114-119.

19. Seitz H, Chrysopoulos A, Egkher E, Mousavi M: [Long-term results of replacement of the anterior cruciate ligament in comparison with conservative therapy]. Chirurg 1994, 65(11):992-998.

20. von Porat $\mathrm{A}$, Roos EM, Roos $\mathrm{H}$ : High prevalence of osteoarthritis 14 years after an anterior cruciate ligament tear in male soccer players: a study of radiographic and patient relevant outcomes. Ann Rheum Dis 2004, 63(3):269-273

21. Wittenberg $\mathrm{RH}, \mathrm{Oxfort} \mathrm{HU}$, Plafki $\mathrm{C}$ : A comparison of conservative and delayed surgical treatment of anterior cruciate ligament ruptures. A matched pair analysis. Int Orthop 1998, 22(3):145-148.

22. Zysk SP, Refior HJ: Operative or conservative treatment of the acutely torn anterior cruciate ligament in middle-aged patients. A follow-up study of 133 patients between the ages of 40 and 59 years. Arch Orthop Trauma Surg 2000, 120(1-2):59-64

23. Frank CB, Jackson DW: The science of reconstruction of the anterior cruciate ligament. J Bone Joint Surg Am 1997, 79(10):1556-1576.

24. Aglietti P, Buzzi R, Zaccherotti G, De Biase P: Patellar tendon versus doubled semitendinosus and gracilis tendons for anterior cruciate ligament reconstruction. Am J Sports Med 1994, 22(2):211-217, discussion 217-218.

25. Almqvist KF, Willaert $P$, De Brabandere $S$, Criel K, Verdonk R: A long-term study of anterior cruciate ligament allograft reconstruction. Knee Surg Sports Traumatol Arthrosc 2009, 17(7):818-822.

26. Asik M, Sen C, Tuncay I, Erdil M, Avci C, Taser OF: The mid- to long-term results of the anterior cruciate ligament reconstruction with hamstring tendons using Transfix technique. Knee Surg Sports Traumatol ArthrosC 2007, 15(8):965-972. 
27. Bach BR Jr, Jones GT, Sweet FA, Hager CA: Arthroscopy-assisted anterior cruciate ligament reconstruction using patellar tendon substitution. Two- to four-year follow-up results. Am J Sports Med 1994, 22(6):758-767.

28. Harner CD, Olson E, Irrgang JJ, Silverstein S, Fu FH, Silbey M: Allograft versus autograft anterior cruciate ligament reconstruction: 3- to 5-year outcome. Clin Orthop Relat Res 1996, , 324: 134-144.

29. Hertel P, Behrend $H$, Cierpinski T, Musahl V, Widjaja G: ACL reconstruction using bone-patellar tendon-bone press-fit fixation: 10-year clinical results. Knee Surg Sports Traumatol Arthrosc 2005, 13(4):248-255.

30. Johnson RJ, Eriksson E, Haggmark T, Pope MH: Five- to ten-year follow-up evaluation after reconstruction of the anterior cruciate ligament. Clin Orthop Relat Res 1984, , 183: 122-140.

31. Jomha NM, Pinczewski LA, Clingeleffer A, Otto DD: Arthroscopic reconstruction of the anterior cruciate ligament with patellar-tendon autograft and interference screw fixation. The results at seven years. $J$ Bone Joint Surg Br 1999, 81(5):775-779.

32. Kleipool AE, Zijl JA, Willems WJ: Arthroscopic anterior cruciate ligament reconstruction with bone-patellar tendon-bone allograft or autograft. A prospective study with an average follow up of 4 years. Knee Surg Sports Traumatol Arthrosc 1998, 6(4):224-230.

33. Krych AJ, Jackson JD, Hoskin TL, Dahm DL: A meta-analysis of patellar tendon autograft versus patellar tendon allograft in anterior cruciate ligament reconstruction. Arthroscopy 2008, 24(3):292-298.

34. Levitt RL, Malinin T, Posada A, Michalow A: Reconstruction of anterior cruciate ligaments with bone-patellar tendon-bone and achilles tendon allografts. Clin Orthop Relat Res 1994, 303: 67-78.

35. Liden M, Ejerhed L, Sernert N, Laxdal G, Kartus J: Patellar tendon or semitendinosus tendon autografts for anterior cruciate ligament reconstruction: a prospective, randomized study with a 7-Year follow-up. Am J Sports Med 2007, 35(5):740-748.

36. Liden M, Sernert N, Rostgard-Christensen L, Kartus C, Ejerhed L: Osteoarthritic changes after anterior cruciate ligament reconstruction using bone-patellar tendon-bone or hamstring tendon autografts: a retrospective, 7-year radiographic and clinical follow-up study. Arthroscopy 2008, 24(8):899-908.

37. Nyland J, Johnson DL, Caborn DN, Brindle T: Internal health status belief and lower perceived functional deficit are related among anterior cruciate ligament-deficient patients. Arthroscopy 2002, 18(5):515-518.

38. Pokar S, Wissmeyer T, Krischak G, Kiefer H, Kinzl L, Hehl G: [Arthroscopically-assisted reconstruction of the anterior cruciate ligament with autologous patellar tendon replacement-plasty. 5 years results]. Unfallchirurg 2001, 104(4):317-324

39. Ruiz AL, Kelly M, Nutton RW: Arthroscopic ACL reconstruction: a 5-9 year follow-up. Knee 2002, 9(3):197-200.

40. Scranton PE Jr, Bagenstose JE, Lantz BA, Friedman MJ, Khalfayan EE, Auld MK: Quadruple hamstring anterior cruciate ligament reconstruction: a multicenter study. Arthroscopy 2002, 18(7):715-724.

41. Shelbourne KD, Stube KC: Anterior cruciate ligament (ACL)-deficient knee with degenerative arthrosis: treatment with an isolated autogenous patellar tendon ACL reconstruction. Knee Surg Sports Traumatol ArthrosC 1997, 5(3):150-156.

42. Strand T, Molster A, Hordvik M, Krukhaug Y: Long-term follow-up after primary repair of the anterior cruciate ligament: clinical and radiological evaluation 15-23 years postoperatively. Arch Orthop Trauma Surg 2005, 125(4):217-221.

43. Taylor DC, Posner M, Curl WW, Feagin JA: Isolated tears of the anterior cruciate ligament: over 30-year follow-up of patients treated with arthrotomy and primary repair. Am J Sports Med 2009, 37(1):65-71.

44. Viola R, Vianello R: Intra-articular ACL reconstruction in the over-40-yearold patient. Knee Surg Sports Traumatol Arthrosc 1999, 7(1):25-28.

45. Ahn JH, Chang MJ, Lee YS, Koh KH, Park YS, Eun SS: Non-operative treatment of $A C L$ rupture with mild instability. Arch Orthop Trauma Surg

46. Barrack RL, Bruckner JD, Kneisl J, Inman WS, Alexander AH: The outcome of nonoperatively treated complete tears of the anterior cruciate ligament in active young adults. Clin Orthop Relat Res 1990, , 259: 192-199.

47. Bonamo JJ, Fay C, Firestone T: The conservative treatment of the anterior cruciate deficient knee. Am J Sports Med 1990, 18(6):618-623.

48. Buss DD, Min R, Skyhar M, Galinat B, Warren RF, Wickiewicz TL: Nonoperative treatment of acute anterior cruciate ligament injuries in a selected group of patients. Am J Sports Med 1995, 23(2):160-165.
49. Engebretsen L, Tegnander A: Short-term results of the nonoperated isolated anterior cruciate ligament tear. J Orthop Trauma 1990, 4(4):406-410.

50. Goldstein J, Bosco JA: The ACL-deficient knee: natural history and treatment options. Bull Hosp Jt Dis 2001, 60(3-4):173-178.

51. Hawkins RJ, Misamore GW, Merritt TR: Followup of the acute nonoperated isolated anterior cruciate ligament tear. Am J Sports Med 1986, 14(3):205-210.

52. Kannus $P$, Jarvinen $M$ : Nonoperative treatment of acute knee ligament injuries. A review with special reference to indications and methods. Sports Med 1990, 9(4):244-260.

53. Kostogiannis I, Ageberg E, Neuman P, Dahlberg L, Friden T, Roos H: Activity level and subjective knee function 15 years after anterior cruciate ligament injury: a prospective, longitudinal study of nonreconstructed patients. Am J Sports Med 2007, 35(7):1135-1143.

54. Lehnert M, Eisenschenk A, Zellner A: Results of conservative treatment of partial tears of the anterior cruciate ligament. Int Orthop 1993, 17(4):219-223.

55. McDaniel WJ Jr, Dameron TB Jr: The untreated anterior cruciate ligament rupture. Clin Orthop Relat Res 1983, , 172: 158-163.

56. Muaidi QI, Nicholson LL, Refshauge KM, Herbert RD, Maher CG: Prognosis of conservatively managed anterior cruciate ligament injury: a systematic review. Sports Med 2007, 37(8):703-716.

57. Neuman P, Englund M, Kostogiannis I, Friden T, Roos H, Dahlberg LE: Prevalence of tibiofemoral osteoarthritis 15 years after nonoperative treatment of anterior cruciate ligament injury: a prospective cohort study. Am J Sports Med 2008, 36(9):1717-1725.

58. Neusel E, Maibaum S, Rompe G: [Results of follow-up of conservatively treated isolated fresh anterior cruciate ligament rupture]. Aktuelle Traumatol 1993, 23(4):200-206.

59. Neusel E, Maibaum S, Rompe G: Five-year results of conservatively treated tears of the anterior cruciate ligament. Arch Orthop Trauma Surg 1996, 115(6):332-336.

60. Noyes FR, Mooar PA, Matthews DS, Butler DL: The symptomatic anterior cruciate-deficient knee. Part I: the long-term functional disability in athletically active individuals. J Bone Joint Surg Am 1983, 65(2):154-162.

61. Paar O, Magin MN: [Possibilities and limits of conservative management of cruciate ligament injuries]. Chirurg 1995, 66(11):1050-1060.

62. Rauch $G$, Wirth $T$, Dorner P, Griss P: [ls conservative treatment of partial or complete anterior cruciate ligament rupture still justified? An analysis of the recent literature and a recommendation for arriving at a decision]. $Z$ Orthop Ihre Grenzgeb 1991, 129(5):438-446.

63. Satku K, Kumar VP, Ngoi SS: Anterior cruciate ligament injuries. To counsel or to operate? J Bone Joint Surg Br 1986, 68(3):458-461

64. Strehl A, Eggli S: The value of conservative treatment in ruptures of the anterior cruciate ligament (ACL). J Trauma 2007, 62(5):1159-1162.

65. Johnson DS, Smith RB: Outcome measurement in the $A C L$ deficient knee-what's the score? Knee 2001, 8(1):51-57.

66. Lysholm J, Gillquist J: Evaluation of knee ligament surgery results with special emphasis on use of a scoring scale. Am J Sports Med 1982, 10(3):150-154.

67. Mohtadi N: Development and validation of the quality of life outcome measure (questionnaire) for chronic anterior cruciate ligament deficiency. Am J Sports Med 1998, 26(3):350-359.

68. Noyes FR, McGinniss GH, Grood ES: The variable functional disability of the anterior cruciate ligament-deficient knee. Orthop Clin North Am 1985, 16(1):47-67.

69. Tegner $Y$, Lysholm J: Rating systems in the evaluation of knee ligament injuries. Clin Orthop Relat Res 1985, , 198: 43-49.

70. Frobell RB, Roos EM, Roos HP, Ranstam J, Lohmander LS: A randomized trial of treatment for acute anterior cruciate ligament tears. $N$ Engl J Med 363(4):331-342.

71. Gianotti SM, Marshall SW, Hume PA, Bunt L: Incidence of anterior cruciate ligament injury and other knee ligament injuries: a national populationbased study. J Sci Med Sport 2009, 12(6):622-627.

72. Prodromos CC, Han Y, Rogowski J, Joyce B, Shi K: A meta-analysis of the incidence of anterior cruciate ligament tears as a function of gender, sport, and a knee injury-reduction regimen. Arthroscopy 2007, 23(12):1320-1325, e1326. 
73. Gottlob CA, Baker $\mathrm{CL}$ Jr: Anterior cruciate ligament reconstruction: socioeconomic issues and cost effectiveness. Am J Orthop (Belle Mead NJ) 2000, 29(6):472-476.

74. Gottlob CA, Baker CL Jr, Pellissier JM, Colvin L: Cost effectiveness of anterior cruciate ligament reconstruction in young adults. Clin Orthop Relat Res 1999, , 367: 272-282.

75. Devlin N, Parkin D: Does NICE have a cost-effectiveness threshold and what other factors influence its decisions? A binary choice analysis. Health Econ 2004, 13(5):437-452.

76. Farshad M, Gerber C, Szucs T, Meyer DC: Determining utility values in patients with anterior cruciate ligament tears using clinical scoring systems. BMC Health Serv Res 2011, 11:182.

77. Chaudhari AM, Briant PL, Bevill SL, Koo S, Andriacchi TP: Knee kinematics, cartilage morphology, and osteoarthritis after ACL injury. Med Sci Sports Exerc 2008, 40(2):215-222.

78. Batiste DL, Kirkley A, Laverty S, Thain LM, Spouge AR, Holdsworth DW: Ex vivo characterization of articular cartilage and bone lesions in a rabbit ACL transection model of osteoarthritis using MRI and micro-CT. Osteoarthritis Cartilage 2004, 12(12):986-996.

79. Cebesoy O: What are the risk factors in the development of osteoarthritis following ACL reconstruction? Int Orthop 2006, 30(5):431, author reply 432

80. Kullmer $K$, Letsch $R$, Turowski B: Which factors influence the progression of degenerative osteoarthritis after ACL surgery? Knee Surg Sports Traumatol Arthrosc 1994, 2(2):80-84.

81. Mihelic R, Jurdana H, Jotanovic Z, Madjarevic T, Tudor A: Long-term results of anterior cruciate ligament reconstruction: a comparison with nonoperative treatment with a follow-up of 17-20 years. Int Orthop 2011, 35(7):1093-1097.

\section{Pre-publication history}

The pre-publication history for this paper can be accessed here: http://www.biomedcentral.com/1472-6963/11/317/prepub

doi:10.1186/1472-6963-11-317

Cite this article as: Farshad et al:: Reconstruction versus conservative treatment after rupture of the anterior cruciate ligament: cost effectiveness analysis. BMC Health Services Research 2011 11:317.

\section{Submit your next manuscript to BioMed Central and take full advantage of:}

- Convenient online submission

- Thorough peer review

- No space constraints or color figure charges

- Immediate publication on acceptance

- Inclusion in PubMed, CAS, Scopus and Google Scholar

- Research which is freely available for redistribution

Submit your manuscript at www.biomedcentral.com/submit 